\title{
Evidence for light-controlled migration amplitude of a sound scattering layer in the Norwegian Sea
}

\author{
Eirik Norheim ${ }^{1}$, Thor A. Klevjer ${ }^{2}$, Dag L. Aksnes ${ }^{1, *}$ \\ ${ }^{1}$ Department of Biology, University of Bergen and Hjort Centre for Marine Ecosystem Dynamics, Bergen 5020, Norway \\ ${ }^{2}$ Institute of Marine Research, Bergen 5005, Norway
}

\begin{abstract}
The oceanic sound scattering layer (SL) is an ubiquitous acoustic signature of mesopelagic fishes and invertebrates that are important food sources for the oceanic macrofauna and players in the biological carbon pump. We investigated the relationship between SL migration amplitude and light in the Norwegian Sea. Incoming surface irradiance was measured continuously during night and day. The increasing latitude of the cruise track facilitated a field experiment wherein night light increased 2 to 3 orders of magnitude during the study period. Concurrent with increased night light, the diel vertical migration amplitude of the SL decreased several hundred meters. The variations in irradiance at the sea surface spanned 6 orders of magnitude during the study period, while the ambient irradiance of the SL mean depth was relatively constant during both day- and nighttime. For the deepest penetrating wavelength $(486 \mathrm{~nm})$, the average ambient light was estimated to be $2 \times 10^{-6} \mathrm{~mW} \mathrm{~m}^{-2} \mathrm{~nm}^{-1}$, which corresponded to a total irradiance of $1.9 \times 10^{-7} \mu \mathrm{mol}$ quanta $\mathrm{m}^{-2} \mathrm{~s}^{-1}$. The observed variation in migration amplitude is consistent with a behavior whereby the SL organisms keep their ambient light intensities within a particular range. We also observed that SL total backscattering, a proxy for biomass, decreased along with the decrease in migration amplitude. We speculate whether this decrease might, in part, relate to a previously proposed 'photoperiod constraint hypothesis' suggesting that high night light intensities in summer at high latitudes limit options for safe foraging in upper layers at night.
\end{abstract}

KEY WORDS: Mesopelagic - Scattering layers - Vertical migration - Light $\cdot$ Norwegian Sea · High latitude

\section{INTRODUCTION}

Studies by Kaartvedt et al. (2012) and Irigoien et al. (2014) have suggested that the mesopelagic sound scattering layers (SL) of the world oceans contain much more biomass than previously assumed. This has led to a renewed interest in factors governing the distribution and the vertical migrations of the mesopelagic SL (Bianchi et al. 2013, Netburn \& Koslow 2015, Bianchi \& Mislan 2016, Klevjer et al. 2016, Røstad et al. 2016). The extreme fluctuations in seasonal light conditions at high latitudes have been hypothesized to limit migration and the distribution of mesopelagic fishes (Kaartvedt 2008), and a better understanding of the SL migration will contribute to a more

\footnotetext{
*Corresponding author: dag.aksnes@uib.no
}

complete understanding of the boreal/arctic ecology of the North Atlantic region. Dickson (1972) reported a striking association between ocean transparency and the daytime depth attained by the SL in the North Atlantic Ocean. Deep SL locations in the daytime and large diel vertical migrations (DVM) were found to be associated with high transparency and vice versa, and it was concluded that light penetration was a dominant factor accounting for the variation in SL daytime depth and migration amplitude. Dickson (1972) noted that although other physical variables may locally affect the extent of the migration, their role is one of secondary importance, modifying, rather than controlling, the pattern of migration. Although a tight relationship between light and

(C) The authors 2016. Open Access under Creative Commons by Attribution Licence. Use, distribution and reproduction are unrestricted. Authors and original publication must be credited. 
the DVM of locally observed scattering layers was known long before (see references in Fornshell \& Tesei 2013), the study of Dickson (1972) appears to be the first to suggest that there might be a common light-forced SL behavior at the ocean basin scale. Evidence for such optical control was also provided by Kaartvedt et al. (1996), who reported that observed SL shoaling off the Norwegian coast was likely due to increased shading from phytoplankton. At the global scale, Bianchi et al. (2013) found that seawater oxygen concentration was the best single predictor of SL migration depth. However, in well oxygenated areas such as the Norwegian Sea, dissolved oxygen is not a likely constraint to the SL organisms.

A major challenge in assessing the potential role of light forcing on the SL is the lack of accurate light characterization down to mesopelagic depths, and proxies for attenuation in the surface layer, like Secchi depth (Dickson 1972) and satellite observations (e.g. Bianchi et al. 2013, Netburn \& Koslow 2015), are often applied. Furthermore, in ecological studies, nights are commonly assumed to be 'dark,' and effects of changes in night light on SL distributions are scarce (but see Benoit-Bird et al. 2009, Prihartato et al. 2015). In the present study, we made use of continuous light and acoustical measurements, during both night- and daytime, to study how variations in SL relate to variations in light and to previously proposed hypotheses on light regulation of mesopelagic organisms.

\section{MATERIALS AND METHODS}

This study was part of the Norwegian Trans-Atlantic Cruise with RV 'G.O. Sars,' which took place from 1 May to 14 June 2013 (Melle 2013). The observations were made in the period 4 to 11 May during the first leg across the Norwegian Sea and into the Icelandic Sea (Fig. 1). We have included a brief description of the distributions of temperature, salinity, chlorophyll (from calibrated fluorescence), and dissolved oxygen based on electronic measurements at the CTD stations listed in Table 1, but more detailed hydrography will be presented elsewhere (T. Klevjer et al. unpublished data). Unfortunately, due to technical problems and reduced trawl sampling capabilities, the composition of the SL could not be established. The glacier lantern fish Benthosema glaciale was the dominant fish in a few trawl samples that were obtained (Norheim 2014), but the observations are insufficient to define the SL composition.

\section{Light measurements}

Downwelling irradiance was measured continuously with a Trios RAMSES ACC hyperspectral radiometer mounted at the top of the ship to minimize influence of artificial light during the night. This instrument also provided measurements of underwater irradiance (Table 1). Irradiance at a wavelength of $486 \mathrm{~nm}$ penetrated deepest (not shown), and this wavelength was applied to estimate the attenuation coefficient for downwelling irradiance. There are 2 reasons for this choice. First, estimates of irradiance at SL depths deeper than the deepest

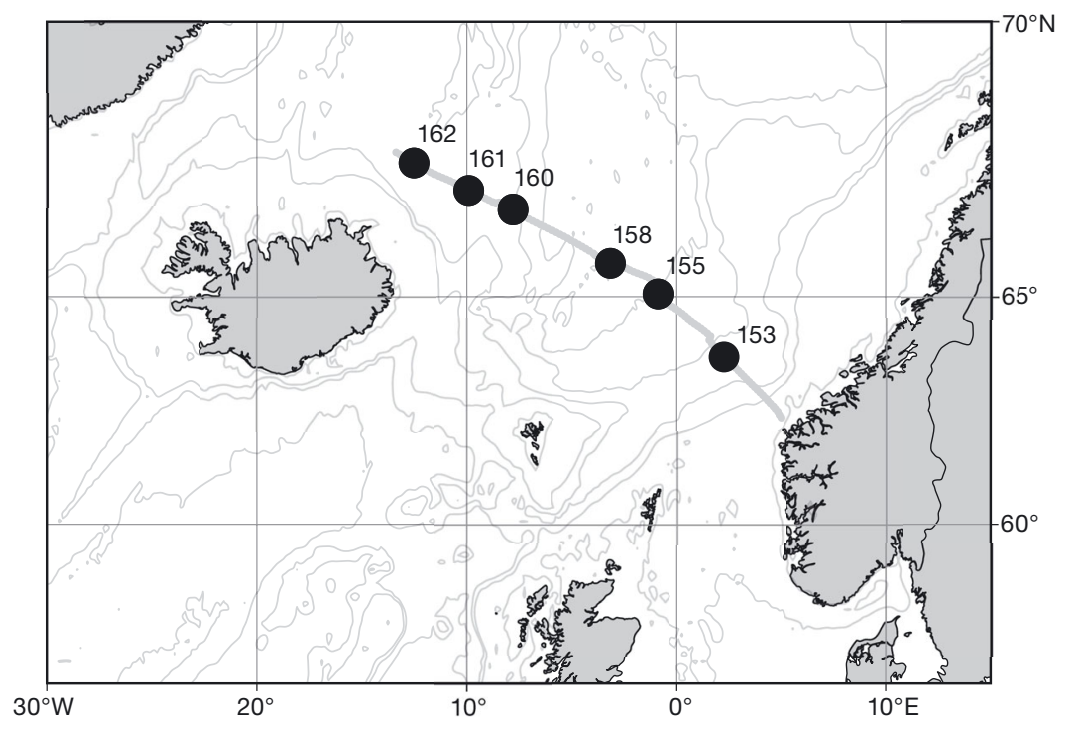

Fig. 1. Study area with cruise track. Numbers refer to the stations listed in Table 1

Table 1. CTD and underwater irradiance stations with maximal lowering depths

\begin{tabular}{|cccccc|}
\hline Station & $\begin{array}{c}\text { Date } \\
\text { (May 2013) }\end{array}$ & Latitude & Longitude & $\begin{array}{c}\text { CTD } \\
(\mathrm{m})\end{array}$ & $\begin{array}{c}\text { Irradiance } \\
\text { measurements } \\
(\mathrm{m})\end{array}$ \\
\hline 153 & 4 & $63^{\circ} 45.81^{\prime} \mathrm{N}$ & $02^{\circ} 45.81^{\prime} \mathrm{E}$ & 1002 & 103 \\
155 & 5 & $65^{\circ} 03.33^{\prime} \mathrm{N}$ & $00^{\circ} 03.33^{\prime} \mathrm{W}$ & 2870 & 167 \\
158 & 7 & $65^{\circ} 40.01^{\prime} \mathrm{N}$ & $03^{\circ} 40.10^{\prime} \mathrm{W}$ & 1002 & 187 \\
160 & 8 & $66^{\circ} 42.25^{\prime} \mathrm{N}$ & $07^{\circ} 42.25^{\prime} \mathrm{W}$ & 1000 & 221 \\
161 & 9 & $67^{\circ} 30.28^{\prime} \mathrm{N}$ & $09^{\circ} 03.28^{\prime} \mathrm{W}$ & 1000 & 231 \\
162 & 10 & $67^{\circ} 33.08^{\prime} \mathrm{N}$ & $1^{\circ} 33.80^{\prime} \mathrm{W}$ & 1000 & 231 \\
\hline
\end{tabular}


underwater light measurements (Table 1) involved extrapolation (see below), and use of the deepest penetrating wavelength minimized the depth range that had to be extrapolated. Second, the average peak sensitivity of rod visual pigments of the Myctophidae, which are known to be an important component of acoustic scattering layers, is close to $486 \mathrm{~nm}$ (Douglas \& Partridge 1997). The attenuation coefficient for downwelling irradiance at $486 \mathrm{~nm}, K$, was estimated according to the model:

$$
E_{z}=E_{0} \mathrm{e}^{-K z}
$$

where $E_{z}$ is the measured downwelling irradiance at depth $z_{1}$ and $E_{0}$ is the irradiance just below the sea surface. Estimates of $K$ were obtained by linear regression analysis with log-transformed irradiance versus depth. Except for the first station (Stn 153), the logarithmic irradiances grouped into an upper and a lower depth layer with different slopes (i.e. K-estimates), and $K$ was estimated separately for these 2 layers (Table 2).

We report irradiance in units of $\mathrm{mW} \mathrm{m}^{-2} \mathrm{~nm}^{-1}$ at $486 \mathrm{~nm}$, but we have also included an estimate of the quantum irradiance as a function of the wavelength distribution as well as the total quantum irradiance of the SL mean depth. This estimate involved calculating the wavelength-specific attenuation coefficients for all wavelengths that could be measured accurately with the instrument in the deepest depth layer (135-231 $\mathrm{m}$ at Stn 161, see Table 2).

\section{Acoustic observations}

Acoustic data were collected with the ship's calibrated Simrad EK60 echosounder system, with the transducers mounted on a drop-keel. This work is based on data from the $38 \mathrm{kHz}$ transducer, integrated in 1 nautical mile (nmi) by $10 \mathrm{~m}$ depth bins, nominally down to a depth of $\sim 900 \mathrm{~m}$, at a threshold of $-82 \mathrm{~dB}$. The large-scale survey system software (LSSS) with KORONA (Korneliussen et al. 2006) was used in the post-processing of data and assignment of acoustic backscatter to acoustic categories, including removal of noise such as noise spikes from other instruments. In LSSS, acoustic data were manually scrutinized, and backscatter was assigned to different acoustic categories based on acoustic appearance and species composition in trawl catches. In the following, we use backscatter assigned to the mesopelagic category, which in the Norwegian Sea is roughly equivalent to backscatter from mesopelagic, non-schooling components at $38 \mathrm{kHz}$. Integration
Table 2. Light attenuation coefficients $(K \pm 95 \% \mathrm{CI})$ estimated from linear regression on log-transformed measurements of downwelling irradiance $(486 \mathrm{~nm})$ versus depth

\begin{tabular}{|lcc|}
\hline Station & Depth layer $(\mathrm{m})$ & $K\left(\mathrm{~m}^{-1}\right)$ \\
\hline 153 & $0-103$ & $0.049 \pm 0.002$ \\
155 & $0-90$ & $0.055 \pm 0.004$ \\
& $90-167$ & $0.044 \pm 0.002$ \\
158 & $0-90$ & $0.070 \pm 0.002$ \\
& $90-187$ & $0.034 \pm 0.001$ \\
160 & $0-110$ & $0.053 \pm 0.004$ \\
& $110-221$ & $0.032 \pm 0.001$ \\
161 & $0-135$ & $0.041 \pm 0.001$ \\
& $135-231$ & $0.032 \pm 0.001$ \\
162 & $0-100$ & $0.046 \pm 0.001$ \\
& $100-231$ & $0.032 \pm 0.002$ \\
\hline
\end{tabular}

results are presented as nautical area scattering coefficients (NASC, $\mathrm{s}_{\mathrm{A}}\left[\mathrm{m}^{2} \mathrm{nmi}^{-2}\right]$ ), while in the echogram (see Fig. 3) we used volume backscattering strengths ( $\mathrm{Sv}$ [ $\mathrm{dB}$ re $\left.1 \mathrm{~m}^{-1}\right]$ ) according to the definitions of MacLennan et al. (2002).

The SL mean depth $\left(Z_{m}\right)$ was calculated according to:

$$
Z_{m}=\sum_{j} \frac{\Delta z_{j} f_{j} z_{j}}{S}
$$

where $f_{j}$ is the NASC quantity for vertical bin $j$ (all vertical bins were $10 \mathrm{~m}$, i.e. $\left.\Delta z_{j}=10 \mathrm{~m}\right), z_{j}$ is the mean depth of bin $j_{1}$, and $S=\sum_{j} \Delta z_{j} f_{j}$, i.e. the total water
column NASC.

\section{Calculation of irradiance at SL mean depth}

We calculated the ambient irradiance, $E_{\text {ambient, of }}$ the SL mean depth according to Eq. (1) by insertion of $Z_{m}$ (from Eq. 2), the $K$-estimate, and the surface irradiance that was measured continuously. At stations with $2 K$-estimates, $K_{1}$ and $K_{2}$ for the upper and lower depth layer, respectively (Table 2), we used $K_{1}$ down through the upper water column, then $K_{2}$ for the lower section, and then $K_{2}$ again to extrapolate beyond the bottom of the lower section, i.e. beyond the depth of the deepest light measurement. In this way, we estimated $E_{\text {ambient }}$ for acoustic registrations that were averaged for every nautical mile. These calculations involve several assumptions, and reported estimates should be considered as order of magnitude estimates. First, we assumed that the $K$ estimates obtained at a particular time were representative throughout day and night. This is a simplification, since $K$ is an apparent optical property being 
affected by variations in the angular distribution of light and surface reflection, and our measurements do not account for such variations. Second, as noted above, in the calculations of $E_{\text {ambient }}$ for depths deeper than the depth of the underwater light measurements, we applied extrapolation of $K$-estimates. Despite these assumptions, we consider this procedure to be more accurate than other attenuation proxies based on near surface associated properties such as ocean color and Secchi depth. For example, the estimated attenuation coefficient in the lower depth layer $(90-187 \mathrm{~m})$ of Stn 158 was $0.034 \mathrm{~m}^{-1}$, while it was twice that $\left(0.070 \mathrm{~m}^{-1}\right)$ above $90 \mathrm{~m}$ depth (Table 2). An attenuation proxy based on remote sensing would likely have been similar to the estimate for the upper layer. Use of this value from the surface and down to e.g. $450 \mathrm{~m}$ provides an $E_{\text {ambient }}$ that is 5 orders of magnitude lower than the one based on the procedure applied in our study.

\section{RESULTS}

\section{Variations in hydrographical factors}

The temperature in the upper $600 \mathrm{~m}$ decreased from $6-7^{\circ} \mathrm{C}$ in the eastern Norwegian Sea to $0-1^{\circ} \mathrm{C}$ in the Icelandic Sea (Fig. 2A), with a concurrent drop in salinity (Fig. 2B). Calibrated fluorescence (Fig. 2C) indicated a pre-bloom situation with maximal chlorophyll values ranging from $0.42 \mathrm{mg} \mathrm{m}^{-3}$ (Stn 162) to $0.94 \mathrm{mg} \mathrm{m}^{-3}$ (Stn 158). Dissolved oxygen concentration was high, above $6.2 \mathrm{ml} \mathrm{l}^{-1}$ in the upper $600 \mathrm{~m}$, at all stations (not shown).
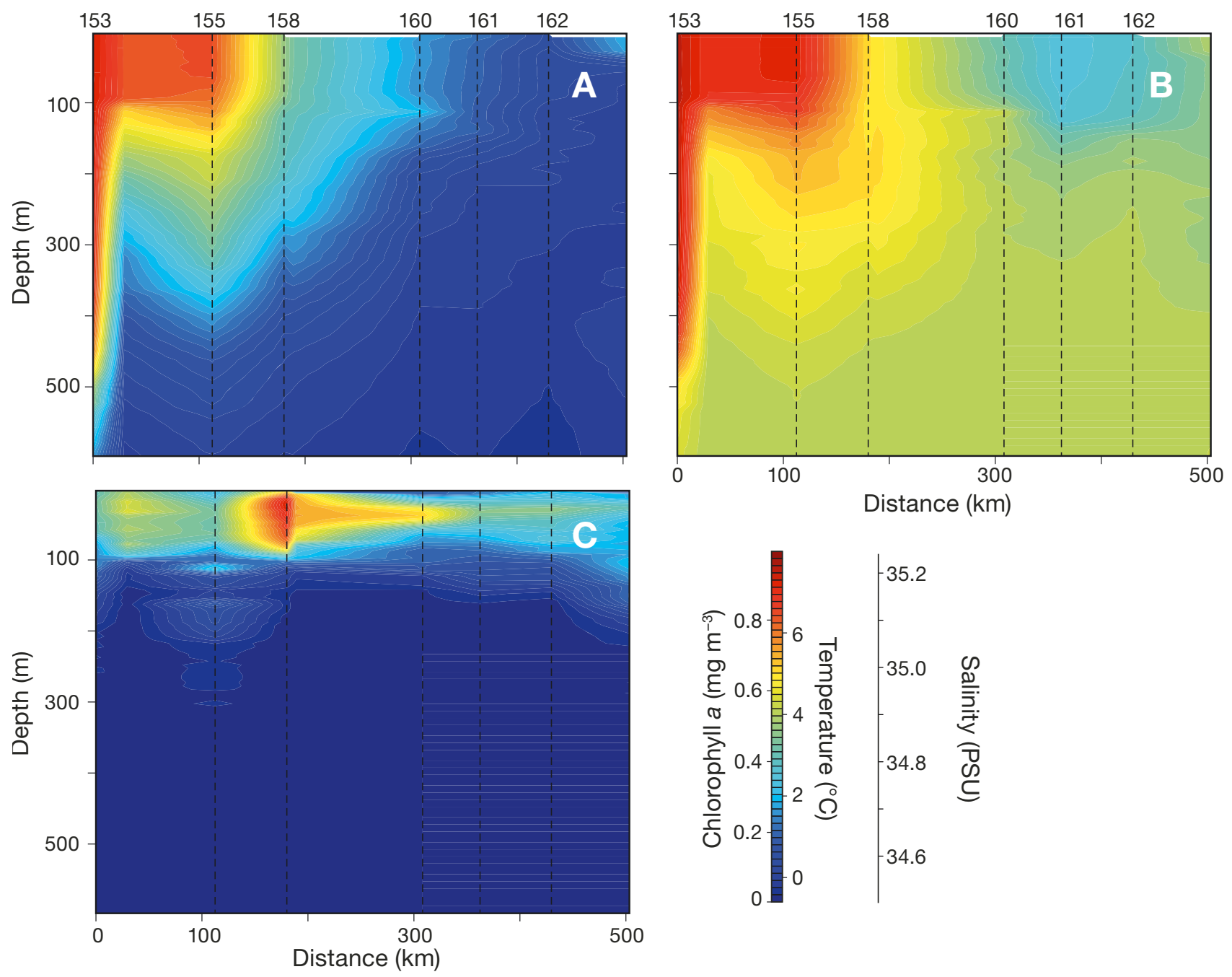

Fig. 2. Vertical distribution of (A) temperature, (B) salinity, and (C) fluorescence along the cruise track. Dashed lines indicate CTD stations with subsurface light measurements (Fig. 1), and the $x$-axis is distance traveled from Stn 153 


\section{Variations in surface irradiance and light attenuation}

The maximal daytime irradiance at $486 \mathrm{~nm}$ above the sea surface varied between 400 and $1400 \mathrm{~mW} \mathrm{~m}^{-2}$ $\mathrm{nm}^{-1}$ (Fig. 3A). This variation reflects changes in cloud cover during the cruise. More noticeable than the daytime variations, however, was the increase in night light towards the end of the study period. This increase is hidden in Fig. 3A (linear scale), but is evident when displayed on a logarithmic scale (Fig. 3B). The minimal night irradiance increased 2 to 3 orders of magnitude as the ship moved into higher latitudes (Fig. 3).

The estimated light attenuation coefficients for downwelling irradiance at $486 \mathrm{~nm}$ ranged between 0.032 and $0.070 \mathrm{~m}^{-1}$ (Table 2). The values for the deepest layer were 39 to $80 \%$ of that estimated for the upper layer.

\section{Variations in SL depth in relation to light}

Two main features are seen in the echogram (Fig. 3C). There is a clear signature of DVM, and the nighttime depth of the SL is approximately $300 \mathrm{~m}$ deeper during the last days, i.e. when the ship was heading northwest (see Fig. 1). This nighttime deepening was correlated with a marked increase (several orders of magnitude) in incoming night irradiance (Fig. 3B). As seen from the coloration in Fig. 3C, the acoustic backscatter became progressively weaker along the cruise line. The surface integrated backscatter (NASC), a proxy for the mesopelagic biomass, decreased from around 360 off Norway (to the left in Fig. 3C) to about 15 north of Iceland (right in Fig. 3C). The relatively strong acoustic backscatter off Norway is spread over a relatively large depth range and appears to be associated with 2 SLs rather the single SL observed later in the cruise (Fig. 3C). As discussed below, we suspect that this pattern involves presence of the pearlside Maurolicus muelleri.

The surface irradiance varied 6 orders of magnitude, between $10^{-3}$ and $10^{3} \mathrm{~mW} \mathrm{~m}^{-2} \mathrm{~nm}^{-1}$, during the study period (Figs. 3B \& 4). This variation was associated with 300 to $400 \mathrm{~m}$ variation in the SL mean depth (Fig. 4A). On average, the SL mean depth deepens $61 \mathrm{~m}$ for each 10-fold increase in surface irradiance (regression line in Fig. 4A). In contrast, the calculated ambient irradiance of the SL mean depth appears relatively constant, with an average of $2 \times$ $10^{-6} \mathrm{~mW} \mathrm{~m}^{-2} \mathrm{~nm}^{-1}$ at $486 \mathrm{~nm}$, although with a slight upward trend (Fig. 4B). The estimated ambient quan-
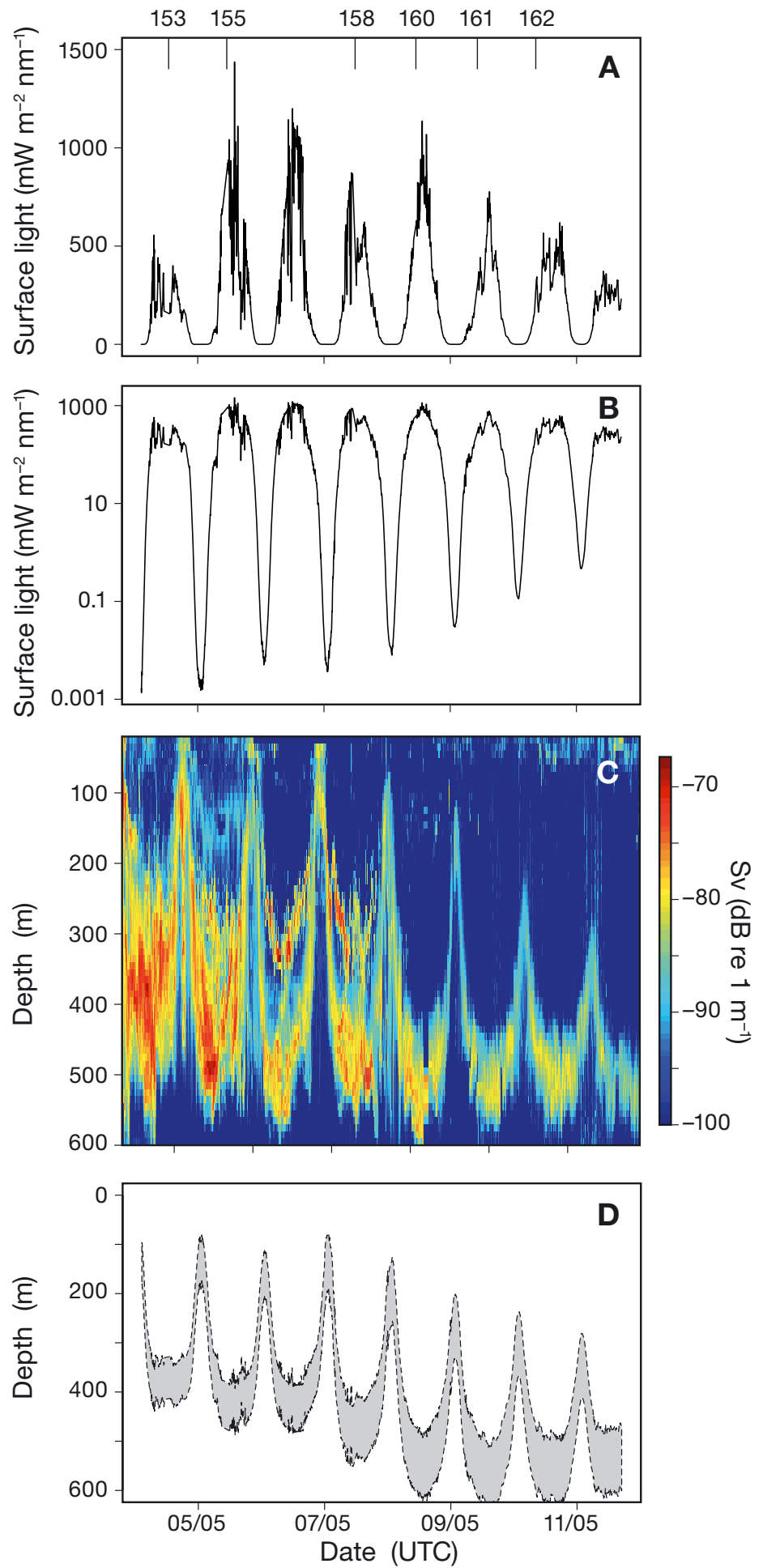

Fig. 3. Variations in $(A, B)$ surface irradiance $\left(\mathrm{mW} \mathrm{m}^{-2} \mathrm{~nm}^{-1}\right)$ at wavelength $486 \mathrm{~nm}$ (A: linear scale, B: logarithmic scale) and in $(\mathrm{C})$ the vertical distribution of the mesopelagic scattering layer given as the volume backscattering strength, Sv (see 'Materials and methods'), as a function of date where UTC is used for time. The shaded area in (D) is the depth range where the underwater irradiance lies between $2.5 \times$ $10^{-7}$ and $1.6 \times 10^{-5} \mathrm{~mW} \mathrm{~m}^{-2} \mathrm{~nm}^{-1}$. Increasing date concurs with the ship's movement in a northwest direction (see Fig. 1) 

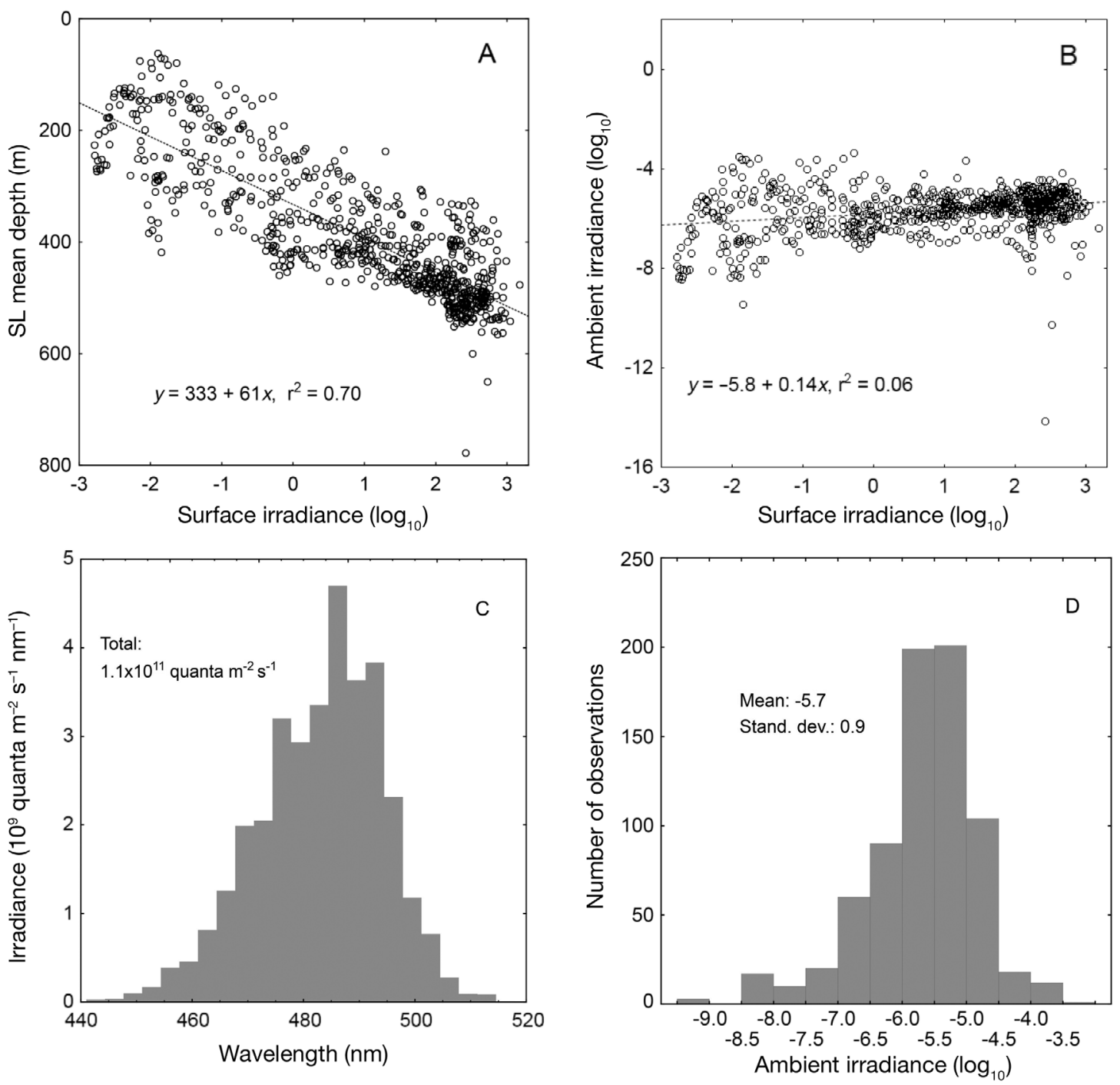

Fig. 4. Scattering layer (SL) (A) mean depth and (B) its ambient irradiance as a function of surface irradiance $\left(\mathrm{mW} \mathrm{m}^{-2} \mathrm{~nm}{ }^{-1}\right.$ at $486 \mathrm{~nm}$ ). (C) Ambient quantum irradiance at SL mean depth as a function of wavelength (see 'Materials and methods'). (D) Frequency distribution of all observations of the logarithmic ambient irradiance (in units of $\mathrm{mW} \mathrm{m}^{-2} \mathrm{~nm}^{-1}$ at $486 \mathrm{~nm}$ ) at the mean SL mean depth with its mean and standard deviation (stand. dev.)

tum irradiance as a function of wavelength, peaking at $486 \mathrm{~nm}$, is shown in Fig. $4 \mathrm{C}$. Integration over the spectrum suggests a total ambient irradiance at the SL mean depth of $1.1 \times 10^{11}$ quanta $\mathrm{m}^{-2} \mathrm{~s}^{-1}$, which corresponds to $1.9 \times 10^{-7} \mu \mathrm{mol}$ quanta $\mathrm{m}^{-2} \mathrm{~s}^{-1}$.

In Fig. 3D, we have illustrated the simulated migration pattern that emerges if the lower and the upper light thresholds are set at $2.5 \times 10^{-7}$ and $1.6 \times 10^{-5} \mathrm{~mW}$ $\mathrm{m}^{-2} \mathrm{~nm}^{-1}$ (at $486 \mathrm{~nm}$ ), respectively. These thresholds correspond to the mean - SD and mean + SD (logarithmic scale) that were estimated from the frequency distribution in Fig. 4D. The simulated dynamics in Fig. 3D are governed by the measured variations in surface irradiance (Fig. 3A) and the measured light attenuation coefficients (Table 2).

\section{DISCUSSION}

Field investigations do not offer the same degree of control as laboratory experiments, and there is no way to exclude the possibility that the observed association between migration amplitude and light is due to correlation with another factor, e.g. temperature. The drop in temperature (Fig. 2A) in the northwesterly direction is a persistent feature of the Norwegian Sea that might affect the SL organisms. However, we are not aware of any hypotheses that connect migration amplitude with temperature changes as observed here. This is in sharp contrast to light, for which several testable hypotheses have been proposed during the last century (reviewed by Cohen \& Forward 2009). 


\section{Light preferendum and light comfort zone hypotheses}

Our results suggest that the observed decrease in migration amplitude is consistent with a migration behavior that keeps the ambient light environment relatively constant. This corresponds to the preferendum or isolume hypothesis (see Cohen \& Forward 2009), implying that vertical migration emerges simply because organisms are attracted to a preferred light level. Instead of being attracted to a specific light level, however, light-driven migration also emerges if organisms distribute within a range of light intensities (Frank \& Widder 2002, Dupont et al. 2009, Staby \& Aksnes 2011). Avoidance, rather than attraction, might be involved. Based on observations of vertical migration in the mesopelagic jellyfish Periphylla periphylla, Dupont et al. (2009) proposed a simple mechanistic migration model where individuals swam (e.g. searching for food by random walk) within a light zone and avoided light levels that were too high, but also those that were too low. These limits were characterized by a maximal and a minimal light threshold, respectively, and the zone in between, such as illustrated in Fig. 3D, can be referred to as the light comfort zone (LCZ) (Røstad et al. 2016). In cases where night light falls below the sensing abilities of the organisms, downwelling irradiance will obviously not be a cue, and dispersion will occur unless other variables provide guidance for where to stay (Dupont et al. 2009). Our observations cannot resolve whether the apparent LCZ involves attraction, avoidance, or both, and future experimental approaches are required to address the proximate mechanism.

Fig. 3D shows the simulated migration pattern for a group of organisms that occupy a constant LCZ ranging 1 logarithmic standard deviation on each side of the estimated mean ambient irradiance of the SL (Fig. 4C). Besides the 2 light threshold parameters, the simulated migration pattern emerges from the observed changes in surface irradiance and the water column light attenuation. The resemblance with the observed pattern (Fig. 3C,D) suggests that the LCZ concept might be an effective way to model SL migrations. Different organisms are likely to have different comfort zones, leading to SLs occupying different depth layers and light intensity zones (Røstad et al. 2016). According to previous studies conducted in fjords and coastal water of Norway, we suspect that the vertically extended SL off Norway (to the left in Fig. 3C) is due to the presence of the pearlside Maurolicus muelleri. This fish is abundant in coastal areas and forms pronounced SLs that are shallower, and consequently exposed to higher light intensities, than e.g. Benthosema glaciale (Giske et al. 1990, Kaartvedt et al. 2009, Staby \& Aksnes 2011, Prihartato et al. 2015).

\section{Photoperiod constraint hypothesis}

The surface integrated backscatter, a proxy for the mesopelagic biomass, decreased by an order of magnitude along the cruise track from Norway to north of Iceland (Fig. 3C). This might be related to a lower productivity in the offshore region, which would support a lower standing biomass of mesopelagic organisms, as broadly indicated by Irigoien et al. (2014) for mesopelagic systems at lower latitudes. However, we are not aware of evidence (Rey 2004) that the productivity of the Norwegian Sea actually decreases along the cruise track (Fig. 1). Our snapshot of the chlorophyll distribution, which at most stations was measured prior to the spring bloom, provides no guidance on the productivity pattern on an annual scale, and it is unclear whether the observed decrease in acoustic backscatter can be related to primary production.

Our observations appear consistent with the 'photoperiod constraint hypothesis' proposed by Kaartvedt (2008), who noted that mesopelagic fish abound in all oceans except the Arctic. According to his hypothesis, their lack of success in this environment is due to inferior feeding conditions imposed by the extreme light climate at high latitudes. It was argued that the midnight sun period in summer limits the options for safe foraging in the upper layers at night, and continuous darkness during winter prevents visual feeding in deep water at any time of day. Our observations were made south of the midnight sun area, but nevertheless in an area where incoming night light is higher than the apparent LCZ of the SL (Fig. 3). Night irradiance at the surface was always higher than $10^{-3} \mathrm{~mW} \mathrm{~m}^{-2} \mathrm{~nm}^{-1}$ at $486 \mathrm{~nm}$ in our study. Thus, surface night light was more than 3 orders of magnitude stronger than the ambient light of the SL mean depth. Hence, our observations are consistent with the assumption of Kaartvedt (2008) that the SL organisms avoided the strong light of the upper water column at night and thereby lost access to safe feeding in this part of the water column. It is perceivable that such reductions in the feeding habitat northwards will at certain latitudes provide insufficient feeding conditions for the fat deposition required to survive a long food-deprived winter. It is 
also of interest to note that, rather than vertically migrating mesopelagic fishes, several of the world's largest fish stocks (i.e. cod, herring, and recently also mackerel), which migrate horizontally over large distances seasonally, have success in utilizing the productivity of the northern latitudes. According to Kaartvedt (2008), it might be speculated that this success is partly governed by reduced competition from mesopelagic fishes for zooplankton. We conclude that our observations are consistent with the LCZ and the photoperiod constraint hypotheses, but acknowledge that this does not exclude other explanations for the observed phenomena.

Acknowledgements. This study was funded by the University of Bergen and the Institute of Marine Research. We thank 4 anonymous reviewers for valuable suggestions.

\section{LITERATURE CITED}

Benoit-Bird KJ, Au WW, Wisdom DW (2009) Nocturnal light and lunar cycle effects on diel migration of micronekton. Limnol Oceanogr 54:1789-1800

Bianchi D, Galbraith ED, Carozza DA, Mislan KAS, Stock CA (2013) Intensification of open-ocean oxygen depletion by vertically migrating animals. Nat Geosci 6:545-548

Bianchi D, Mislan KAS (2016) Global patterns of diel vertical migration times and velocities from acoustic data. Limnol Oceanogr 61:353-364

Cohen JH, Forward RB (2009) Zooplankton diel vertical migration - a review of proximate control. Oceanogr Mar Biol Annu Rev 47:77-109

> Dickson RR (1972) On the relationship between ocean transparency and the depth of sonic scattering layers in the North Atlantic. J Cons Int Explor Mer 34:416-422

Douglas RH, Partridge JC (1997) On the visual pigments of deep-sea fish. J Fish Biol 50:68-85

> Dupont N, Klevjer TA, Kaartvedt S, Aksnes DL (2009) Diel vertical migration of the deep-water jellyfish Periphylla periphylla simulated as individual responses to absolute light intensity. Limnol Oceanogr 54:1765-1775

Fornshell JA, Tesei A (2013) The development of SONAR as a tool in marine biological research in the twentieth century. Int J Oceanogr 2013:678621

Frank T, Widder E (2002) Effects of a decrease in downwelling irradiance on the daytime vertical distribution patterns of zooplankton and micronekton. Mar Biol 140: 1181-1193

Giske J, Aksnes DL, Baliño BM, Kaartvedt S and others (1990) Vertical distribution and trophic interactions of zooplankton and fish in Masfjorden, Norway. Sarsia 75 : 65-81

Editorial responsibility: Alejandro Gallego, Aberdeen, UK
Irigoien X, Klevjer TA, Røstad A, Martinez U and others (2014) Large mesopelagic fishes biomass and trophic efficiency in the open ocean. Nat Commun 5:3271, doi: 10.1038/ncomms4271

> Kaartvedt S (2008) Photoperiod may constrain the effect of global warming in arctic marine systems. J Plankton Res 30:1203-1206

Kaartvedt S, Melle W, Knutsen T, Skjoldal HR (1996) Vertical distribution of fish and krill beneath water of varying optical properties. Mar Ecol Prog Ser 136:51-58

Kaartvedt S, Røstad A, Klevjer TA, Staby A (2009) Use of bottom-mounted echo sounders in exploring behavior of mesopelagic fishes. Mar Ecol Prog Ser 395: 109-118

Kaartvedt S, Staby A, Aksnes DL (2012) Efficient trawl avoidance by mesopelagic fishes causes large underestimation of their biomass. Mar Ecol Prog Ser 456:1-6

Klevjer TA, Irigoien X, Røstad A, Fraile-Nuez E, BenítezBarrios VM, Kaartvedt S (2016) Large scale patterns in vertical distribution and behaviour of mesopelagic scattering layers. Sci Rep 6:19873

Korneliussen RJ, Ona E, Eliassen I, Heggelund Y and others (2006) The Large Scale Survey System - LSSS. Proceedings of the 29th Scandinavian Symposium on Physical Acoustics, Ustaoset, 29 January - 1 February 2006. Available at http://dwoc07ze9j3lr.cloudfront.net/143875 7001/p2006_sspa_korneliussen_et_al_lsss.pdf

> MacLennan DN, Fernandes PG, Dalen J (2002) A consistent approach to definitions and symbols in fisheries acoustics. ICES J Mar Sci 59:365-369

Melle W (2013) Survey report. Norwegian Trans Atlantic Cruise with R/V G.O. Sars. Institute of Marine Research, Bergen

Netburn AN, Koslow JA (2015) Dissolved oxygen as a constraint on daytime deep scattering layer depth in the southern California current ecosystem. Deep-Sea Res I Oceanogr Res Pap 104:149-158

Norheim E (2014) Distribution of mesopelagic scattering layer (MSL) in relation to the physical environment in the Norwegian Sea. MSc thesis, University of Bergen

Prihartato PK, Aksnes DL, Kaartvedt S (2015) Seasonal patterns in the nocturnal distribution and behavior of the mesopelagic fish Maurolicus muelleri at high latitudes. Mar Ecol Prog Ser 521:189-200

Rey F (2004) Phytoplankton: the grass of the sea. In: Skjoldal HR (ed) The Norwegian Sea ecosystem. Tapir Academic Press, Trondheim, p 97-136

Røstad A, Kaartvedt S, Aksnes DL (2016) Light comfort zones of mesopelagic acoustic scattering layers in two contrasting optical environments. Deep Sea Res I Oceanogr Res Pap 113:1-6

Staby A, Aksnes DL (2011) Follow the light-diurnal and seasonal variations in vertical distribution of the mesopelagic fish Maurolicus muelleri. Mar Ecol Prog Ser 422: 265-273

Submitted: November 16, 2015; Accepted: April 12, 2016 Proofs received from author(s): May 21, 2016 